\title{
On the economics of fixed-mobile convergence
}

\author{
Theodoros Rokkas, Dimitris Varoutas, Dimitris Katsianis, Timo Smura, Kumar Renjish, \\ Mikko Heikkinen, Jarmo Harno, Mario Kind, Dirk Von Hugo and Thomas Monath
}

Theodoros Rokkas, Dimitris Varoutas and Dimitris Katsianis are all based at the University of Athens, Athens, Greece. Timo Smura, Kumar Renjish and Mikko Heikkinen are all based at the Helsinki University of Technology, Espoo, Helsinki, Finland. Jarmo Harno is based at Nokia Siemens Networks, Espoo, Finland. Mario Kind, Dirk Von Hugo and Thomas Monath are all based at T-Systems, Berlin, Germany.
The authors would like to acknowledge the support, ideas and contributions of their colleagues from

EUREKA/CELTIC project ECOSYS. Part of this work was supported by European Social Fund and by the Greek General Secretariat for Research and Technology and he private sector, under Measure 8.3 of Operational Programme "Competitiveness,"

3rd Community Support

Framework

Received 15 May 2008 Revised 30 September 2008 Accepted 25 November 2008

\begin{abstract}
Purpose - The purpose of this paper is to show that fixed-mobile convergence (FMC) has gathered much interest in the telecommunications industry lately. Integrated operators (who own both fixed and mobile networks), are keen to exploit FMC benefits in order to save costs and generate new revenues. This paper aims to analyze the effects of converged network and service environment on the business of existing telecommunication operators.
\end{abstract}

Design/methodology/approach - After an introduction to the regulatory, market, and technology related issues of convergence, the authors focus on analyzing the role of FMC technologies and services in their businesses of an integrated operator with existing fixed and mobile operations in a large Western European country.

Findings - Results reveal that an integrated operator can benefit from cost savings, customer retention and prevent revenue erosion by migrating to FMC.

Originality/value - This paper examines the effects of fixed-mobile convergence to an integrated operator.

Keywords Economics, Telecommunications, Mobile communication systems

Paper type Research paper

\section{Introduction}

Telecommunications operators are facing major changes as traffic and revenues are moving away from the traditional fixed circuit-switched PSTN networks and services towards mobile and broadband services and the IP-based packet-switched networks. Both residential and business users are rapidly adopting new, more advanced services there is also an increasingly demand of access to services regardless of place or time. Furthermore, the trend seems to be towards bundling of communications services into triple-play (broadband data + telephony + television) or quadruple-play (mobile included) packages. Until now traditionally separated markets, networks, and business units of companies are converging, i.e. approaching one another.

Although the direction is clear, the optimal roadmaps and timing are not. On one side, operators have to consider cannibalization effects when new services are introduced to the market. On the other side, slow migration might give an advantage to competing service offerings, with result the loss of market shares. Uncertainty about the "dominant designs" in network architectures and service platforms increases the likelihood of wrong decisions, and as the investments in question are very large, careful and systematic assessment is required to avoid costly consequences.

Many operators are currently planning to upgrade their networks towards convergent architectures in order to provide convergent services. As fixed PSTN traffic is decreasing 
faster and faster, a main motivation for fixed operators is to create substitution revenue, trying to reduce their losses. The situation looks better for the mobile market which continues growing. Mobile services, used at home, at the office, and outdoors is bringing larger and larger part of the revenues.

Convergence can occur at different levels. There is convergence of content/services, of transport/software, as well as of equipment/hardware. Although these levels are interrelated, convergence at the content or service level does not require convergence at the transport level (network convergence) and network convergence does not necessarily imply convergence of services.

The study focuses on analyzing the effects of converged network and service environment on the business of existing telecommunication operators. More specifically it focusses on analyzing the role of fixed-mobile convergence (FMC) technologies and services in the businesses of an integrated operator with existing fixed and mobile operations in a large Western European country. The study provides a techno-economic viewpoint on fixed mobile convergent architecture, based on IMS. Our studies combine market forecasts, OPEX and CAPEX estimates, and revenue forecasts, in order to draw conclusions on the net effect of the FMC decision. An earlier version of this paper was presented at CTTE 2007 (Renjish et al., 2007) and PIMRC 2007 (Rokkas et al., 2007) conferences.

The organization of this paper is as follows: Section II presents an overview about the regulation, the key drivers and the motivations towards the migration to FMC, in the case of an integrated operator. Section III outlines the framework, and assumptions considered for this business case study. Section IV presents the results and analysis of the case followed by conclusions in Section VI. Finally in the Appendix are presented issues concerning the FMC architecture.

\section{Background}

\section{Regulation issues}

Regulation evolves in response to market and technological development. Regulators must ensure that access to networks and services of potentially dominant providers in a relevant broadband market will satisfy requirements for openness and non-discrimination. However, regulation should be adjusted or removed when it can be a barrier for technological development. Current regulation is particularly related to service provisioning and interconnection. Regulation concerning fixed-mobile convergence should be elaborated. FMC leads to the development of new services that can be used with one device, anywhere, anytime, using fixed or mobile networks. The present regulatory rules cannot be applied as such to FMC services. In a convergence environment, regulation should allow setting the right incentives for investment into new infrastructures.

The main regulation issues concern the rights/obligations for the operation having a significant market power, interconnection charging arrangements between fixed and mobile services, access tariffs, numbering plan, fixed/mobile number portability.

Convergence of services has an impact on interconnection. The regulation of interconnection of telephone services and the interconnection of internet services are very different. Telephone services regulation is cost price based, while internet services has been rather unregulated.

Convergence has created a number of new products, more or less successful, with or without public support. An appropriate infrastructure enabling operators the provisioning of these products is generally required. The customer premises equipment should be also adapted to handle the services.

In some cases, VolP offerings escape the current regulation which has been elaborated for traditional telephony. The European Commission and the National Regulatory Authorities in several countries had recently addressed VolP services within a new regulatory framework. 
While this matter has not been fully treated, there is a kind of consensus that VolP services should not be regulated on the same basis as PSTN services and that the regulation imposed on VolP should be minimal.

Convergence challenges the universal service obligations in several manners. Funding a universal service can be obtained through extra charges imposed on certain services, for instance on service interconnection. But funding a particular service (e. g. VolP) can be questionable when it is provided in conjunction with other services. Then, regulators must consider new offerings carefully.

Regarding convergence, it is not clear whether broadband access should be a universal service, or not. If, currently, broadband accesses are not available to a large majority of the population, they become more and more essential for education, public health, to avoid social exclusion, and so on. Not having any regulation on broadband accesses may result in market distortion and delay in provisioning of infrastructure.

The European broadband markets have increased rapidly over the last years, along with an increasing competition among technologies. Regulatory intervention on broadband markets concerns mainly access networks. Regulation is supposed first of all to undertake consumer's defense, but it is intended to guarantee access of both new network operators and service providers to essential facilities and networks controlled by incumbents, which are the usual target of regulators. Recent trends indicate a more technical approach of broadband service regulation. The best regulatory approach to be adopted depends on the characteristics of each country, such as whether competing broadband infrastructure exist already or not.

Concerning convergent service markets, NRAs have new responsibilities regarding the coordination, supervision and application of the legislation related to the broadband environment. The responsibility should cover first network and service regulation for both telecommunications and broadcasting and, if it is the case cover content regulation.

\section{Migration to FMC}

In this study we aim to evaluate, model, quantify and identify migration-convergence paths towards a common platform for fixed and mobile networks and services, considering the different existing infrastructure deployments. We will try to identify and describe the business opportunities of an evolutionary path from the present situation which is defined by almost independent business models for PSTN, Mobile, and fixed broadband operators to fixed mobile converged situation. Our focus is on the incumbent network operator case that plays an important role in the telecommunication environment.

In order to obtain the maximum possible benefits a new framework for the migration to converged networks and services is needed. The expectation is that players in the telecommunication industry will change their network-oriented perspective to a service oriented perspective. Therefore it will create new opportunities for the entrance of new players in the game such as service providers, application developers and consequently new business models will be created.

In today's competitive telecommunications market the independent business units for PSTN, Mobile and fixed Broadband are trying to reduce their costs and find alternative, more optimised ways of doing business, furthermore fixed incumbent network operators are facing decrease in circuit-switched service usage and subscriber numbers. FMC is expected to reduce some costs by network optimisation and to achieve new revenue potentials by introducing new value added services to the customers.

The customers also expect advantages from the FMC. The expectation of voice call price reduction caused by Voice over IP (VoIP) compared to the circuit-switched services (PSTN, ISDN) is the main one. Customers do not like to think about which network is cheapest and at what time, simplicity is one key and the harmonisation of price levels for voice calls. 
Additional values for the customers include, e.g. a single contract for all services, as well as ubiquitous access in general (fixed, in-house, nearby and on the move).

From the operators' perspective, new FMC-enabled features like ubiquitous access and new value added services are expected to fill at least a part of the revenue gap. Of course, the demand for higher bandwidth in general plays an important role in this context too.

\section{FMC players and drivers}

The ongoing convergence between telecom and internet markets will bring forth new market players, complementing as well as challenging the existing telecom players. The value network is opening up from the earlier closed monopolistic operator dominated market bringing forth new opportunities for innovative new players competing for the customers.

The FMC ecosystem consists of the following players, each aiming to gain a share of the value generated:

- access and core network operators;

- backbone network transport operators;

- service delivery platform developers:

- content providers that may produce content applicable for FMC devices;

- service operators offering value-added services to the end-users;

- software manufacturers providing client software for efficient switching between multiple radio technologies, terminal operating systems, and desktop SW vendors;

- handset manufacturers producing multi-radio handsets or smart cards;

- network vendors;

- national regulatory and competition authorities.

The need for FMC deployment is driven from different quarters. Some of the key drivers are as follows:

- Industry drivers. From the industry's view-point some of the main drivers are: cost savings, by eliminating redundancies and harmonizing the network and service management; faster time-to-market by having the ability to provision new and advanced services over multiple end-user devices simultaneously; and the ability to retain customers' loyalty by making access to services easy and simple.

- Technology drivers. Some of the main drivers are: the progress in standardization and implementation of enabling technology platforms such as IP Multimedia Subsystem (IMS) (3GPP, 2007); availability of a growing number of multi-radio handsets.

- Market drivers. Some of the main drivers are: the customer demand for ubiquitous access of advanced content and services; single authentication, authorization and accounting (AAA) capabilities; ease of use.

IMS is considered as the key platform required for migration to a fully-functional FMC. However, operators have already taken the first step towards FMC with the deployment of transition technologies such as unlicensed mobile access/generic access networks (UMA/GAN) (3GPP, 2006). Examples of some such services are: BT's Fusion (BT Fusion, 2006), NTT DoCoMo's (2004) PASSAGE DUPLE, and TDC's Duet (2006). The National Regulatory Authorities (NRAs) globally are following these developments and working towards amending existing policies and creating new ones that can enable the industry players in creating value which will also benefit the end-users. 


\section{Business case analysis}

\section{The business case framework}

An integrated operator is characterized as the owner of both fixed and mobile networks in a market, with a clear separation of the fixed and mobile operations' business units, i.e. each having its own customer care, marketing, subscription management, network and service provisioning units. Traditionally, an integrated operator has been one of the incumbents in the market, often having a leading market share. The main reason for an incumbent network operator to provide convergent services is to retain (or gain) market shares in a market steadily exposed to more and more competition. Many new actors are entering the role of telecommunication such as MVNOs, mobile and fixed services providers, new broadband providers, VolP providers, and lately also many new actors entering the WiFi business. The competition for the customer is very hard. However, ownership of the customer is a vital asset for all operators. As the usage price of telecommunication is decreasing, the subscription fee becomes more important as the main source of revenue. Avoiding churn by bundling fixed and mobile services and enhancing the user experience by value added services, such as presence information, better location information, one handset for all services, same service on different devices etc, are aspects the customer might find attractive and will pay for.

In order to solve these issues, the integrated operators are motivated to deploy FMC, which will enable the provisioning of advanced multimedia services easily and efficiently with a shorter time to market, across multiple access networks (with a common IP-based core network). Such services are expected to retain the loyalty of customers, reducing the churn and generating new sources of revenue.

The following sections elaborate the study of an integrated operator's migration to FMC. The study investigates the impact on profitability, and discusses the related issues and possible solutions.

\section{FMC framework}

In the following sections an integrated operator, with ownership of both fixed and mobile networks (access, transport and core) is considered. Such an operator may offer mobile services in the outdoor areas, while in the indoor areas, the services offered are a combination of digital subscriber line (xDSL) and wireless local area networks (WLANs), along with some WLAN hotspots for the popular public areas like airports, parks etc.

In order to achieve FMC, both networks are based on IP. The IMS platform specifies interoperability and roaming, provides charging and security, thus making it easier to achieve service interoperability across different operators in terms of connectivity. The integrated operator will have a better potential compared to pure-play fixed or mobile operators, present only in the fixed or mobile business, to offer a single bill, single number, as well as a set of services that may be delivered independently of terminal and location.

\section{Key assumptions}

FMC services offered. The difference between real converged products and commercial bundles that are simply marketed as converged offerings lies in whether new functionalities are added or not and whether services are integrated. For the customer, a product like voice call will not necessarily appear radically different in terms of functionality. However, the price will be different. For the operator, the converged service enabling voice (VoIP) is produced through new technology. The migration scenarios for convergence imply a transformation from bundling to real integration.

The service modeling is an essential part of the scenario description. The starting point for the FMC products is a converged voice product, which is enhanced over time with more bandwidth demanding data services. In the beginning customers may choose one of the four packages that the FMC operator will offer. These are named FMC Bronze, Silver, Gold 
and Platinum respectively. All of the packages include fixed voice with unlimited national calls while the initial tariff for the base packet (bronze) is set to $45 €$ per month. The Silver packet includes fixed broadband internet and $20 \mathrm{MB}$ of free mobile data access per mont for $61 €$, the gold has $200 \mathrm{MB}$ of mobile data for $81 €$ and finally in the platinum the free mobile data are $2 \mathrm{~GB}$ and is given at $106 €$ per month.

In addition each of the above packages also include new FMC services (e.g. free access to Wi-Fi spots, location services, instant messaging etc) for free as part of the bundling. The reasoning behind such free FMC services in the early stages of FMC introduction is to attract customers to these packages. The initial monthly tariff has calculated as the sum of each separate subscription tariff (fixed voice, mobile voice, fixed BB and mobile data packet) minus a reduction and the aforementioned prices decline with an average percentage of 3 percent per year.

In Table I the expected distribution of users that will use the FMC products, among the different offered packages is presented. In the beginning the "low" cost packets will attract customers but over the years there will be a change in favor of the packets that offer free mobile data also. In the end of the study period the gold packet is expected to attract most of the customers (45 percent).

OPEX considerations. The OPEX costs for an integrated operator can be divided in to five general categories. These are described as follows:

1. Network related elements: includes all the necessary costs for network operation, OSS operation, maintenance and repair of the network elements, equipment and software licences, rental of network resources, costs for site rental and electricity.

2. Marketing and sales related elements: costs regarding sales and marketing, customer acquisition and subsidisation.

3. Customer service related elements: costs associated to customer care, charging, billing, call center.

4. IT, support and service development related elements: includes service management, design and development of new services, Business IT, management support, costs regarding the purchase of licenses for content delivery.

5. Interconnection and roaming costs: termination fees for calling or completing a call or a session originated or terminated in another network.

Geographical and economic considerations. For the market a modeling a "Large" western European country is assumed, similar to Germany, Italy, French or UK. The market figures are calculated as the averages of these countries.

The total population is $65,200,000$ (with a yearly growth of 0.3 percent), in the average household stay 2.3 persons and the surface area is approximately $370,000 \mathrm{~km}^{2}$. In long-term analyses, a study period of at least seven years is used. In this case of fixed mobile convergence, a study period of 8 years is assumed to be suitable with starting and ending years as 2008 and 2015 respectively.

This scenario focuses on calculating the effect of one integrated operator's decision, whether to migrate to FMC or not, on its overall business. Only the differences (i.e. delta)

Table I Services distribution over the study period

\begin{tabular}{lrrrrrrrr} 
& 2007 & 2008 & 2009 & 2010 & 2011 & 2012 & 2013 & 2014 \\
\hline FMC Bronze (\%) & 40 & 35 & 31 & 28 & 25 & 20 & 15 & 10 \\
FMC Silver (\%) & 50 & 49 & 45 & 33 & 26 & 24 & 22 & 20 \\
FMC Gold (\%) & 9 & 13 & 15 & 24 & 31 & 36 & 41 & 45 \\
FMC Platinum (\%) & 1 & 3 & 9 & 15 & 18 & 20 & 22 & 25
\end{tabular}


between the non-FMC and FMC case are considered, revenues and costs that would exist regardless of FMC are not treated separately. At the beginning of the study period the operator has two options: either he will implement FMC, begin the installation of the various IMS network elements and start offering new services or continue with the existing situation, meaning, the operator will continue to operate two independent networks.

\section{Results and discussion}

The advantage of network and service convergence for an integrated operator will be reflected in the economic results of a business case comparison between the FMC and the non-FMC cases. This difference is revealed in the operators' investments i.e. capital expenditure (CAPEX) and operational expenditure (OPEX), as well as market share and service demand figures, and is furthermore reflected at the generated revenues.

The business opportunities for the incumbent integrated operator are handled in a conservative way, i.e. the market share within a competitive environment is assumed to remain constant at 33 percent, an annual tariff reduction from 5 percent to 1 percent are expected until the end of the study period. Migrating to FMC is the mean for the operator to retain the revenue at the same levels as now, because if not a market share loss is expected due to the competition (the competitors will implement FMC) and so the revenue losses. Adding FMC services to its operation will not attract new customers but the growth in FMC customers will mainly come from customers converting from the operators own customer base. In addition, growth will be influenced by the general market interest of telecom services. The estimation for the FMC customers is based on predictions regarding the penetration of IMS capable terminals and IMS service demand (Figure 1).

In the case of going to FMC initially the operator will face some revenue loss since the tariffs for the new products will offered with a discount compared to the sum of the mobile and fixed tariffs in the non-FMC case.

OPEX breakdown over the whole study period is presented at Figure 2, the major contributors are marketing and sales (38 percent) and IT support (25 percent), while customer care, network maintenance and interconnection have 12 percent each. Roaming and expected interconnection models for IP networks are still uncertain and may not differ very much from the non-FMC situation, whereas figures for marketing will increase in the beginning as new products and services have to be promoted. The overall saving increases towards the end of the study period because the number of converged customers will be then considerable to the total portion of customers. The costs regarding to customer care will increase the first because of the introduction of new services, but over the time will decline. This is due to the fact that at the existing situation (no FMC) operator having two distinctive networks must provide support to a customer for these two separate networks. From the

Figure 1 IMS capable terminals prediction

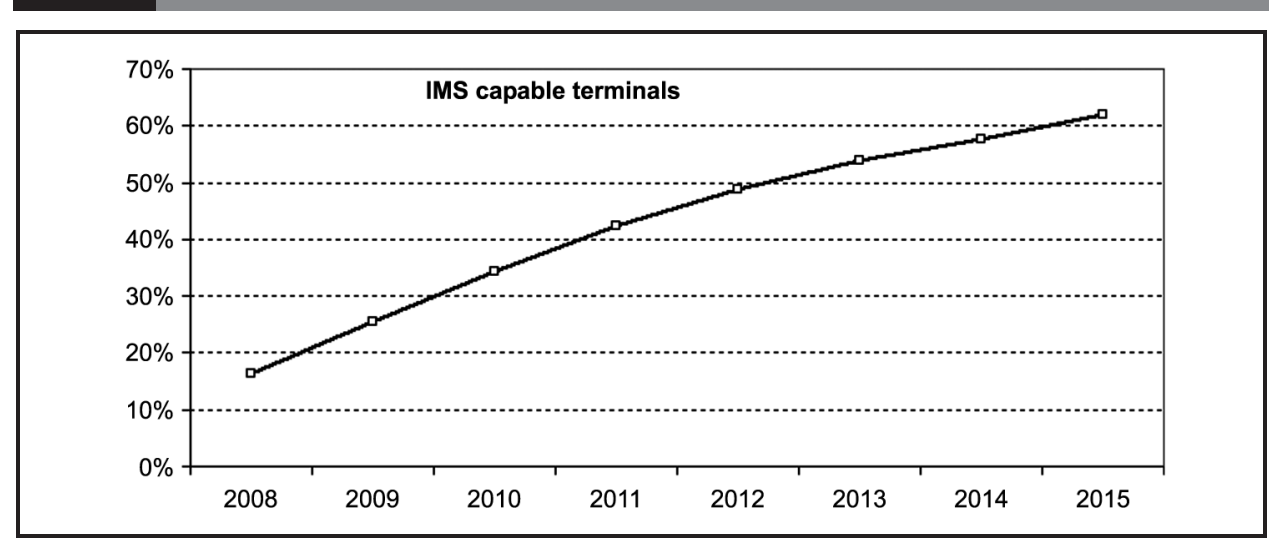

VOL. 11 NO. $32009 \mid$ info $\mid$ PAGE 81 


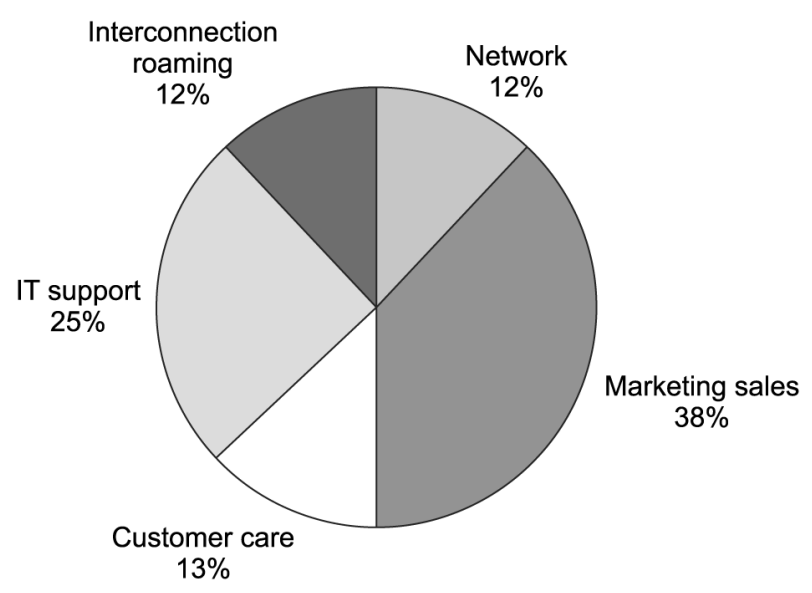

results one can see that after the first years the operator will reduce its OPEX compared to the non-FMC situation. The trend in the OPEX savings is growing more even after the study period, giving a considerable competitive advantage for the integrated operator selecting the FMC path. Central packet switching (PS) signaling and circuit switching (CS)-PS interconnection functions will be the main sources for additional CAPEX elements for the integrated FMC operator, but these investments are minor compared to OPEX.

Since we consider here a "delta case" compared to a pure GSM operation, there will not be many CAPEX elements relevant for the business case related to investments in GSM. However, it will be necessary with some updates due to the implementation of IMS. Compared to small FMC-investments which are only related to the FMC customers (without consideration of existing PSTN migration towards VolP) the major potential of FMC lies in savings in OPEX. At the end of the study period, the yearly OPEX savings due to convergence are almost 7 percent of the total yearly OPEX of the operator.

The modeling outcome shows that the FMC case achieves positive results as a whole (see Figure 3). The higher spending in the early period, when migrating to IMS, together with savings in the later phase result together into $249 \mathrm{M€}$ Net Present Value (NPV), as the positive additional value generated by the IMS project. This includes the slight revenue degradation because of price reductions in the bundles provided. In addition to this positive result, we have to take into account that the FMC operator is foreseen to keep its market share, which is seen to be probably an even more important factor for the future position, as compared to an integrated operator not going for convergence. Note that the results have been obtained for a large Western European country with slowly growing population and a high mobile subscribers' penetration rate starting already at 86 percent.

However, there are many sources of cost uncertainty dependent on the existing architectural structures of the operator. These include support function upgrades, service realization aspects and service usage. Operators with outdated legacy systems will face higher additional costs than operators with up-to-date modern systems.

In addition to the above cost-revenue comparison relating to FMC implementation, we estimate that if the integrated operator does not invest in FMC, it will start losing customers to other operators that are driving FMC (Figure 4). We estimate that in the non-FMC operator case the market share in all sectors, mobile, fixed voice and BB goes down due to competition and lower price bundles offered by the FMC operators. This negative effect for the non-FMC business case is probably even more significant in the competition than the considerable OPEX savings in favor of the FMC alternative presented above. 


\section{Economic Results (FMC)}

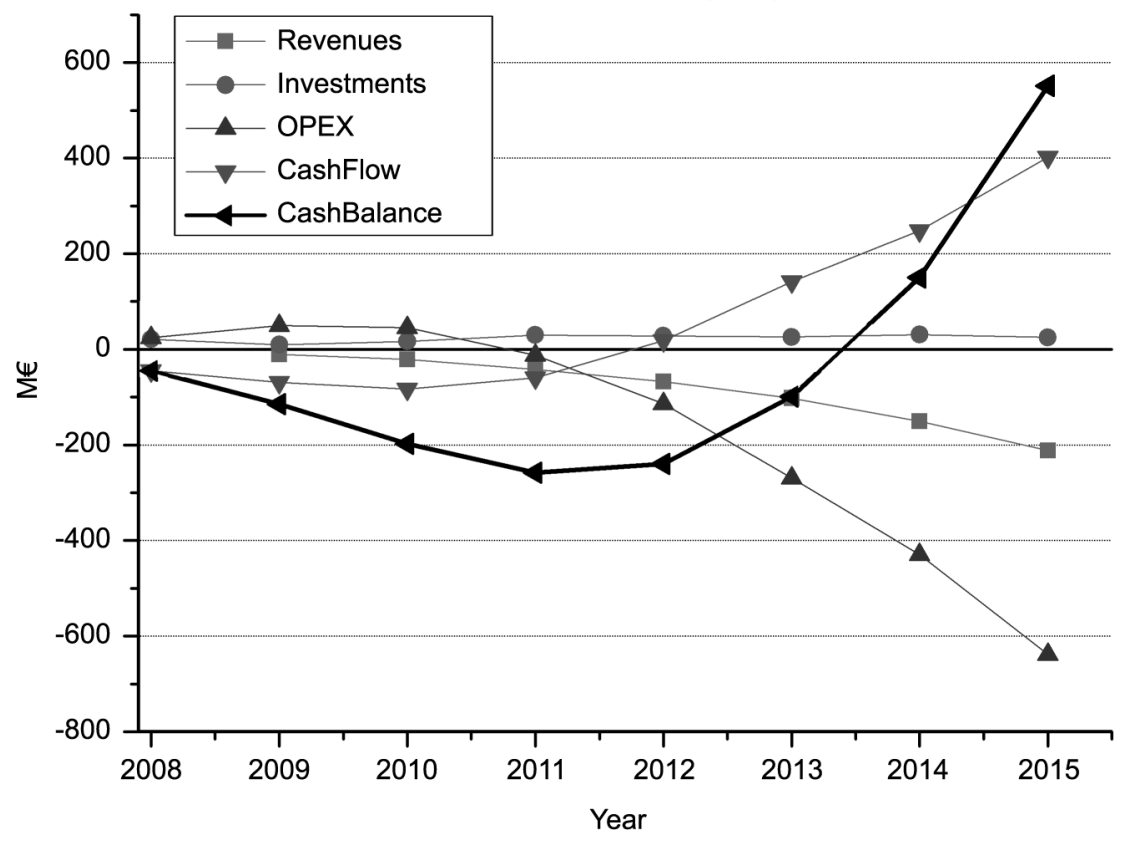

\section{Figure 4 Market share development in the non-FMC case}

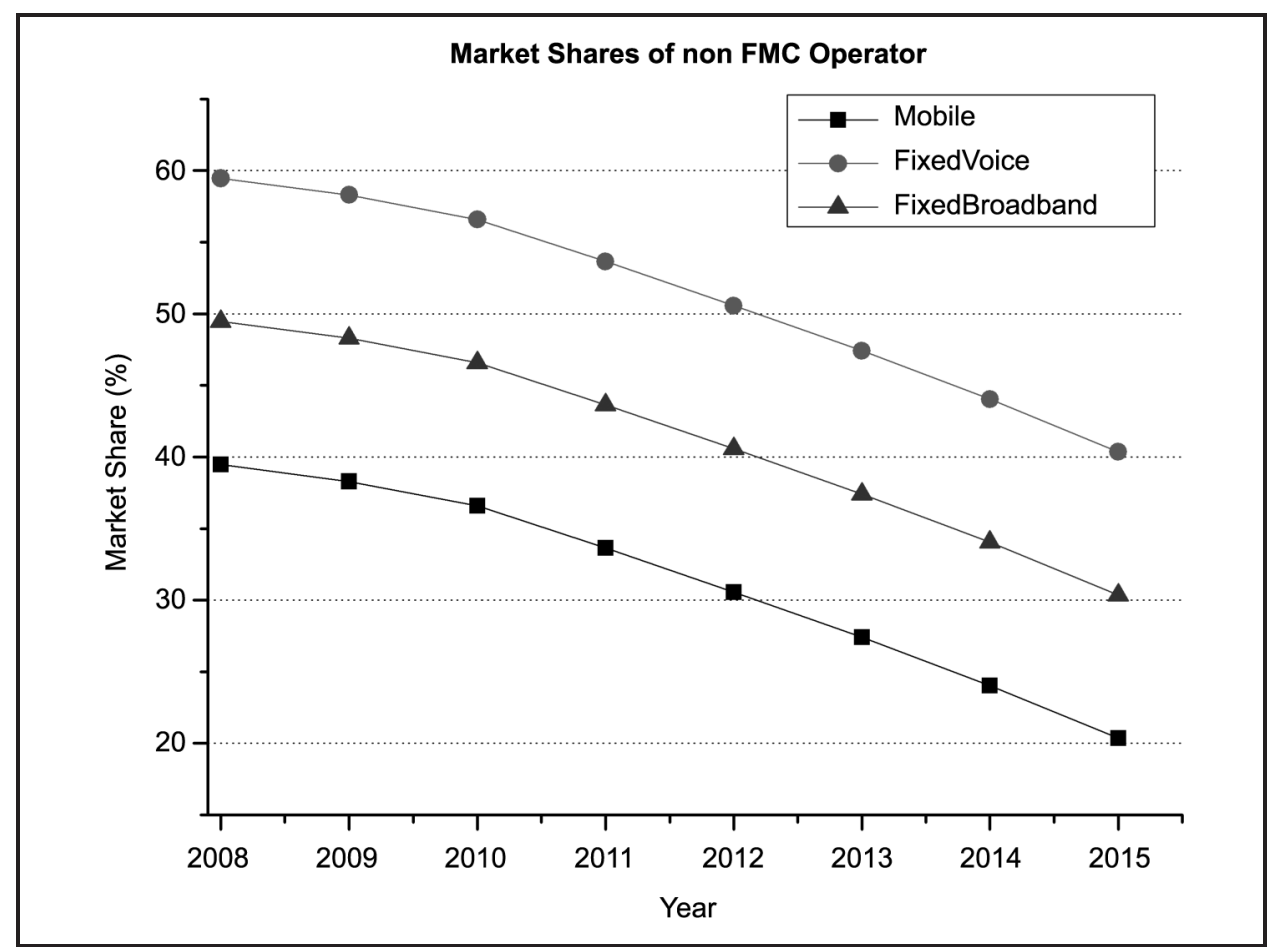

VOL. 11 NO. $32009 \mid$ info $\mid$ PAGE 83 
Nowadays an incumbent fixed network operator faces the challenges of growing competition by new entrants in the form of (internet) service providers and meanwhile well established mobile operators with lower operational costs and generally higher flexibility to market dynamics. According to the results of this study, the negative effect of correspondingly resulting customer and revenue loss can be partly compensated by the introduction of FMC and the integration and cooperation of the fixed network operations with a mobile counterpart.

Note that the expected reduction of OPEX, thanks to IP-based next generation network and service management, does also apply without decision for FMC, but will not countermeasure expected revenue loss alone. Only together with the use of common interoperable standards for both the fixed and mobile networks and their integration, at least at the level of common service provisioning platforms (application plane), to simplify deployment of intuitively usable converged services (SMS, voice mail etc), and with unified marketing (single bill) of fixed-mobile converged services will the customer attractiveness and OPEX savings increase to stabilize revenue and customer figures.

Further investigations are required to assess the impact of new integrated network and service platforms on the overall system performance (QoS), security, scalability and the potential for easy and fast deployment of new services (service modeling).

Thus an integrated operator may gain a unique selling opportunity to differentiate itself from competitors' offerings. Less conservative assumptions with regard to market development, and prolongation of the study period would result in an even more positive business case for FMC, but also increase uncertainty of the study.

\section{Conclusions}

The significance of FMC is today a subject of debate as the interest gathers momentum. Players in the FMC ecosystem are identifying strategies to maximize their benefits from such deployments. Integrated operator is currently facing many issues for which migration to FMC is considered as a solution. Analysis of the results shows increasing cost savings in terms of OPEX in later years of the study period and is expected to continue further, thus giving the integrated operator a competitive advantage to other players in the market. Another benefit is the possibility to retain its market share, which has much wider impact on profitability compared to cost savings. This also enables the operator to reduce revenue erosion from existing services by introducing packages with FMC services. Further work is required to consider other aspects of FMC such as the benefits of integrated service delivery platform for service provisioning and their effect on the overall business. The main learning from the investments modelling is that central PS signalling and CS-PS interconnection functions will be the main source of CAPEX costs for an integrated FMC operator. However, there are many other sources of cost uncertainty dependent on the existing architectural structures of the operator. These include support function upgrades, service realization aspects and service usage. The extensity of updates due to IMS is highly dependent on operator and service requirements. The actual service usage is the main source of uncertainty for investments modelling. Although it has been assumed that voice calls will play a dominating role also in the future, which is very likely to occur.

\section{References}

3GPP TR 23.806 (2005), Voice Call Continuity between CS and IMS Study (Release 7).

3GPP TS 43.318 (2006), Generic access to the A/Gb interface; Stage 2 (Release 7).

3GPP TS 23.228 (2007), IP Multimedia Subsystem; Stage 2 (Release 8).

BT Fusion (2006), available at: www.bt.com/btfusion/

ECOSYS (2006), "Techno-ECOnomics of integrated communication SYStems and services - ECOSYS", available at: www.celtic-ecosys.org/ 
NTT DoCoMo DoCoMo, N.T.T. (2004), PASSAGE DUPLE, available at: www.nttdocomo.com/pr/2004/ 001193.html

Renjish, K.K.R., Rokkas, T., Varoutas, D., Kind, M., Hugo, D., Harno, J., Smura, T. and Heikkinen, M. (2007), "Fixed-mobile convergence: an integrated operator case study" paper presented at the 6th Conference on Telecommunication TechoEconomics CTTE 2007, Helsinki, 14-15 June.

Rokkas, T., Katsianis, D., Varoutas, D. and Sphicopoulos, T. (2007), Fixed mobile convergence for an integrated operator: a techno-economic study", paper presented at the IEEE Annual International Symposium on Personal Indoor and Mobile Radio Communications (PIMRC 2007), Athens, 3-7 September.

TDC's Duet (2006), available at: http://privat.tdc.dk/mobil/duet/

\section{Appendix}

\section{FMC}

In the modelling of integrated operator's migration to FMC, two key enablers, IMS and UMA/GAN were considered. We will try to describe briefly the functionalities, dimensioning and other assumptions of the different elements constituting IMS and UMA/GAN. For more information, refer ECOSYS deliverables 18 and 22 (ECOSYS, 2006).

\section{IMS architecture}

The IMS architecture used for the model is shown in Figure A1, where functionalities are mapped to physical components. The user equipment (UE) accesses IMS through an access network. The heart of the IMS system is the call session controller (CSC). It is connected to a home subscriber server (HSS) and two media controllers: the media resource function controller (MRFC) and media gateway controller (MGC). AS refers to a generic application solution which would basically be a service delivery platform (SDP) offering both operator's own and third-party services. Support functions (SF) are an estimate of necessary PS transfer (TSF) and business support system (BSS) upgrades due to IMS. Voice call continuity (VCC) (3GPP, 2005) functions are provided for seamless voice call handover in different access networks both in CS and PS domains.

\section{Figure A1 IMS architecture}

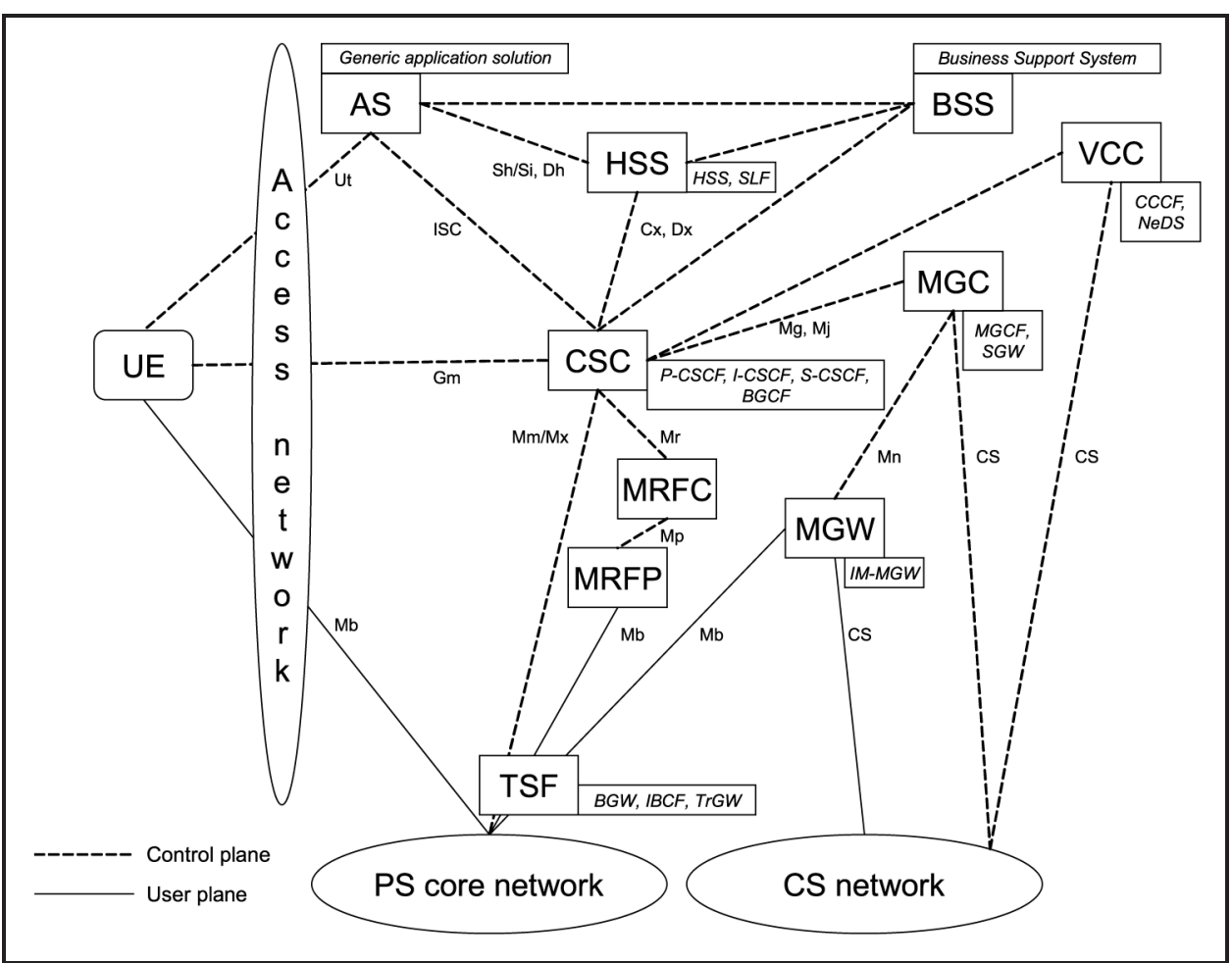

VOL. 11 NO. 32009 |info $\mid$ PAGE 85 

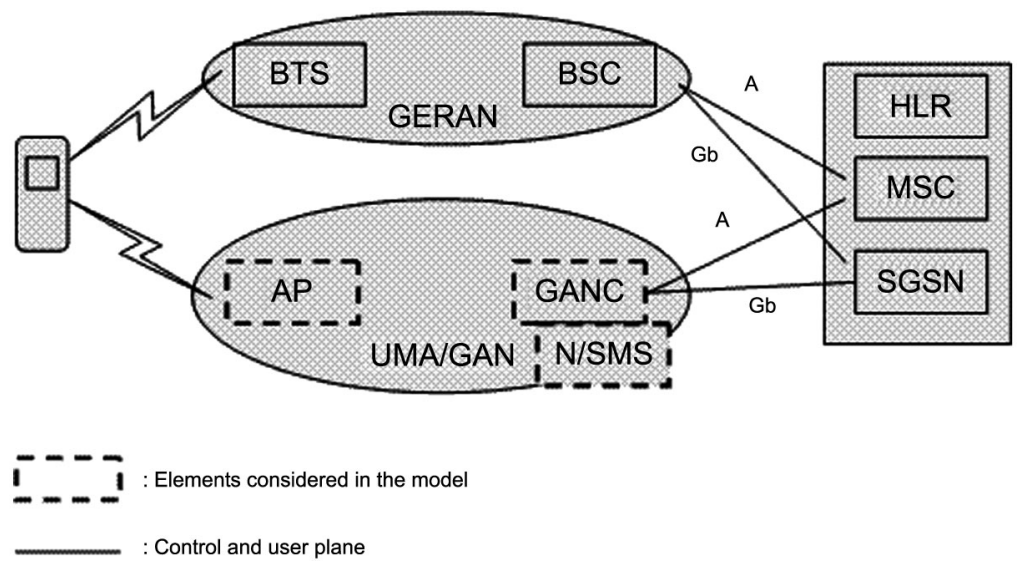

\section{UMA/GAN architecture}

UMA/GAN is a mechanism at the access network, which enables the seamless provisioning of circuit-switched (CS) services (such as GSM voice calls) over packet-switched (PS) unlicensed WLANs and broadband networks. Current 3GPP standard for UMA/GAN (3GPP, 2006) supports GSM and GPRS services (via the A/Gb interface). Support for WCDMA (Iu interface) is expected in the future. In our case, UMA/GAN is deployed as an interim solution (before IMS VCC is deployed in 2009) for providing seamless voice services across the CS GSM network and homes with WLANs attached to broadband access. Such a seamless provisioning of voice calls enable operators to add value to the existing voice service of customers (by offering lower priced calls at home) and also manage traffic effectively.

The UMA/GAN architecture considered for the model is shown in Figure A2.

The key architectural elements considered in our study for UMA/GAN are as follows:

- Access Point (AP). An AP operates at the unlicensed $2.4 \mathrm{GHz}$ and $5 \mathrm{GHz}$ spectrums offering a local area network access to mobile handsets. These APs support IEEE 802.11 $a, b$ and $g$ standards. A single site may have one or more APs depending on the capacity of each AP and the traffic demand.

- Generic access network controller (GANC). A GANC acts as an aggregator of APs and performs authorization, authentication and accounting (AAA) functionalities for the customers accessing services through APs. GANC is the equivalent of base station controller (BSC) in GERAN.

- Network/service management system (N/SMS). An N/SMS element consists of network and service related management systems essential for managing the GANCs and services offered over APs.

To purchase reprints of this article please e-mail: reprints@emeraldinsight.com Or visit our web site for further details: www.emeraldinsight.com/reprints 